\title{
Phytochemical composition of wormwood (Artemisia gmelinii) extracts in respect of their antimicrobial activity
}

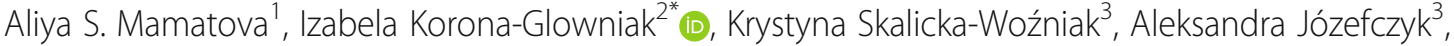 \\ Krzysztof K. Wojtanowski ${ }^{3}$, Tomasz Baj ${ }^{3}$, Zuriyadda B. Sakipova ${ }^{1}$ and Anna Malm²
}

\begin{abstract}
Background: Extracts from medicinal plants with phytochemicals with known antimicrobial properties can be an effective adjunct in the complex treatment of infectious diseases. This study aimed to evaluate the antimicrobial activity of wormwood extracts collected in Kazakhstan (Artemisia gmelinii Weber ex Stechm.), along with their phytochemical analysis.
\end{abstract}

Methods: The ethanolic and chloroform extracts were subjected to HPLC combined with quadrupole time-of-flight mass spectrometry method. For quantitative assessment of antimicrobial activity, minimal inhibitory concentration (MIC) of the tested extracts was determined by micro-dilution broth method for the panel of the reference microorganisms. Minimal bactericidal concentration (MBC) or minimal fungicidal concentration (MFC) were also determined.

Results: LC/MS analysis showed the presence of 13 compounds in the tested extracts, including flavonoids: apigenin, luteolin, rutin, two O-methylated flavonols (isorhamnetin, rhamnazine), coumarin compounds (umbelliferone, scopoletin and scopolin (scopoletin 7-glucoside), 3-hydroxycoumarin and 4-hydroxycoumarin), chlorogenic acid and two dicaffeoylquinic acid isomers. Quantitative HPLC analysis showed that umbelliferone was dominant in the chloroform extract while chlorogenic acid was identified as a main compound in the ethanolic extract. The antibacterial and antifungal activity of chloroform and ethanolic extracts was comparable. The most sensitive were the Gram-positive bacteria represented by staphylococci, Micrococcus luteus and Bacillus spp. $(\mathrm{MIC}=1.25-5 \mathrm{mg} / \mathrm{ml})$ and yeasts represented by Candida spp. $(\mathrm{MIC}=2.5-5 \mathrm{mg} / \mathrm{ml})$, irrespective of the assayed extract.

Conclusions: Extracts of wormwood Artemisia gmelinii have shown a wide spectrum of antibacterial and antifungal activity. Luteolin, rutin, isorhamnetin and scopolin were identified in A. gmelinii species for the first time. The determining of the most potential compounds of Artemisia gmelinii can be used to develop effective antibacterial and antifungal agents.

Keywords: Artemisia gmelinii, Asteraceae, Phytochemical analysis, Antimicrobial activity

\footnotetext{
* Correspondence: iza.glowniak@umlub.pl

2Department of Pharmaceutical Microbiology with Laboratory for

Microbiological Diagnostics of Medical University of Lublin, 1 Chodzki Street,

20-093 Lublin, Poland

Full list of author information is available at the end of the article
}

(c) The Author(s). 2019 Open Access This article is distributed under the terms of the Creative Commons Attribution 4.0 International License (http://creativecommons.org/licenses/by/4.0/) which permits unrestricted use, distribution, and reproduction in any medium, provided you give appropriate credit to the original author(s) and the source, provide a link to the Creative Commons license, and indicate if changes were made. The Creative Commons Public Domain Dedication waiver (http://creativecommons.org/publicdomain/zero/1.0/) applies to the data made available in this article, unless otherwise stated. 


\section{Background}

Artemisia gmelinii Webb \& Stechmann, also known as Gmelin's wormwood, is one from over 500 species in the genus Artemisia (Asteraceae). It is a perennial plant, reaching up to $50-150 \mathrm{~cm}$ of height, richly-branched, grayish-brown color, strongly woody at the bottom. Taproot with a thickness of $3-5 \mathrm{~cm}$. Leaves are thick and mossy especially on the underside, however loosely on the upper side. Inflorescences are spherical (20-30 in head), small, slightly drooping, densely arranged, gathered in a short panicles. The fruit is achene $(1,5 \mathrm{~mm})$ finely - striped, brown. They bloom from August to October [1, 2]. The plant occurs on the dry stony and rocky slopes, hills, semi-deserts, grasslands, wastelands, at the altitude of $1500-4900 \mathrm{~m}$ asl from Eastern Europe to Central Asia, China, Mongolia and Korea. Brought to the area of the United States, growing endemically in the state of Ohio. The plant's preference is a sandy and loamy, well drained soil [2].

The leaf and stem are used in Korea to treat hepatitis, hyperlipaemia and infected cholecystitis with flavonoids and sesquiterpenes being suggested as bioactive constituents. Dried parts of the plant have been applied in Tradition Chinese Medicine for treatment and prevention of chronic inflammations of the liver [3]. As the mechanism of action the inhibitive effects of lipid peroxidation and the downregulation of TNF- $\alpha$ mediated apoptosis were suggested [3].

Biologically active substances (BAS) derived from medicinal plants can be an effective adjunct in the complex treatment of infectious diseases [4-7]. Different Artemisia species are described as producers of metabolites with antimicrobial and antioxidant activity. They were reported for high content of alkaloids, flawonoids, phenol, quinines and terpenoids [8-10]. Phytochemical studies concerning phytochemical composition of $A$. gmelini are rather partial. So far 1,8 - cineol (21-40\%), camphora (10-31\%), borneol (4-17\%) were detected as main compounds in essential oil [11], as well as polyphenolic components such as scopoletin, chlorogenic acid, 4',7- di-O-methyl-apigenin, acacetin and 4',5,7 trihydroxy-3',6-dimethoxyflavon [12], caffeic acid, 4-Ocaffeoylquinic acid, luteolin-7-O-glucoside, and apigenin7-O-glucoside, 3,5-O-dicaffeoylquinic acid and its ethyl ester derivatives [13] were indicated as dominant compounds of Artemisia gmelinii.

As A. gmelinni is distributed widespread in the area of Kazakhstan and both composition and application are not well defined, the aim of the present studies was the evaluation of the antimicrobial activities of extracts of wormwood collected in Kazakhstan (Artemisia gmelinii Weber ex Stechm.) along with their preliminary phytochemical analysis.

\section{Methods}

\section{Plant material and extraction}

The aerial parts of wormwood were collected in July and August 2015 in the generative phase at the foothills of the Trans-Ili Alatau of the Republic of Kazakhstan. Raw material drying was carried out by air-shadow method, in the well-ventilated accommodations, out of direct sunlight. The harvesting was produced in accordance with the principles of the GACP standard. The collected raw materials were identified in accordance with the requirements of the State Pharmacopoeia of the Republic of Kazakhstan by Danylov Mikhail Petrovich, botanic specialist in Botanical Garden, Institute of Botany and Phytointroduction of Kazakhstan Academy of Sciences in Almaty, Kazakhstan. The vouchers have been deposited in herbarium of Institute of Botany and Phytointroduction of Kazakhstan Academy of Sciences, receiving identification numbers ASM-AG 2015/01.

A technology for obtaining dry extract from the raw material of wormwood with the use of $70 \%$ ethanol by percolation has been developed. Extraction of BAS was due to convective diffusion to complete depletion, then further purification and thickening of the extract to a moisture content of no more than 5\% (dry extract) was carried out. The method of obtaining $100 \mathrm{~g}$ of dry extract from $4 \mathrm{~kg}$ of raw materials consisted of the following steps: soaking of raw materials, maceration pause (infusion), percolation (direct transition of the extractant through the raw material layer), purification and thickening of the extract as well as identification of the extract. The extract output was $2.5 \% \pm 0.26$.

The preparations of $30 \mathrm{~g}$ of thick extract from $1455 \mathrm{~g}$ of raw material by the method of circulation extraction with the use of a volatile chloroform solvent were carried out in a classical manner in a "Soxhlet" type installation. The resulting thick extract was a viscous mass of dark brown color, with a specific smell of a bitter taste. The extract output was $2.1 \% \pm 0.71$.

Exactly $20 \mathrm{mg}$ of each extracts were weighed and then dissolved in $10 \mathrm{ml}$ of a mixture of methanol-water $8: 2 \mathrm{v} /$ v. Extracts were subjected to fingerprint analysis with application of HPLC after passing syringe filters (PTFE, $0.45 \mu \mathrm{m})$.

\section{Reagents}

Standard substances for HPLC analysis were purchased in the Sigma-Aldrich ${ }^{\oplus}$ Co. and ChromaDex Inc.

\section{HPLC analysis}

Extracts were analyzed using an Agilent Technologies 1100 liquid chromatograph with a visible diode - array detector (DAD) equipped with Zorbax Eclipse XDB C8 column (150 X $4.6 \mathrm{~mm}$ I.D., $\mathrm{dp}=5 \mu \mathrm{m})$ with gradient elution: $\mathrm{A}$ - water $+1 \%$ acetic acid; $\mathrm{B}$ - acetonitryle 
(0 min- $10 \% \mathrm{~B} ; 0-10 \mathrm{~min}-10-14 \% \mathrm{~B} ; 10-25 \min -14-$ $30 \% \mathrm{~B} ; 25-35 \mathrm{~min}$. - 30-35\% B; 35-50 min. - 35-60\% B; 50-57 min. $60 \%$ B). Injection volume for extracts and standards was $10 \mu \mathrm{L}$. The flow rate was $1 \mathrm{ml} / \mathrm{min}$ and column thermostat temp. $25^{\circ} \mathrm{C}$. The identification of the compounds was performed by comparing retention times and UV-DAD spectra $(\lambda=254,280$ and 325 $\mathrm{nm}$ ) with those for standard solutions. Quantitative determination was performed on the basis of 3-fold determinations of the tested compounds. Determination of the content of the tested compounds in individual extracts was determined with the use of calibration curves and calculated mathematically. Calibration plot was prepared of five different concentrations $(1,0.75,0.5,0.25,0.1 \mathrm{mg}$ per $10 \mathrm{~mL}$ for all investigated coumarins, phenolic acids and flavonoids. In the HPLC-DAD analysis of compounds of examined extract calibration plots were highly linear $-\mathrm{R}^{2}>$ 0,9932 for phenolic acids $R^{2}>0,9966$ for flavonoids and $R^{2}>0,9867$ for coumarins.

\section{LC-MS analysis}

The purified samples were analysed quantitatively by an HPLC/ESI-QTOF-MS system in positive ion mode using a 6530B Accurate-mass-QTOF-MS (Agilent Technologies, Inc., Santa Clara, CA, USA) mass spectrometer with an ESI-Jet Stream ion source. The chromatograph was equipped with DAD detector, autosampler, binary gradient pump, and column oven. Gradient of solvents: acetonitrile (1\%) with $10 \mathrm{mM}$ ammonium formate $(0.1 \%)$ (solvent A) and acetonitrile (95\%) with $10 \mathrm{mM}$ ammonium formate $(0.1 \%)$ (solvent $B$ ) were used as the mobile phases. The following gradient procedure was adopted: 010 min, $10-14 \%$ of (B); $10-15$ min, $14-22 \%$ (B); $15-25$ min, 22-30\% (B), 25-35 min, 30-35\% (B),35-45 min 35$55 \%$ (B), 45-47 $\mathrm{min}, 55-65 \%$ (B) and 47-48, 65-80\% (B). Total time of analysis was $48 \mathrm{~min}$, with a stable flow rate at $0.200 \mathrm{~mL} / \mathrm{min}$. Injection volume for extracts was $10 \mu \mathrm{L}$. ESI-QTOF-MS analysis was performed according to the following parameters of the ion Source: Dual spray jet stream ESI, positive and negative ion mode, gas (N2) flow rate: $12 \mathrm{~L} / \mathrm{min}$., nebulizer pressure: $35 \mathrm{psig}$, vaporizer temp.: $300{ }^{\circ} \mathrm{C} ; \mathrm{m} / \mathrm{z}$ range $100-1000$ mass units, with acquisition Mode AutoMS/MS, collision induced dissociation (CID): $200 \mathrm{eV}$ with MS scan rate 1 spectrum per s, 2 spectra per cycle, skimmer: $65 \mathrm{~V}$, fragmentor: $150 \mathrm{~V}$ and octopole RF Peak: 750 V. Qualitative and quantitative analysis of the extract from TF was made additionally in auto MS/MS with excluded: $\mathrm{m} / \mathrm{z}$ at 922.0097 and 121.0508 for positive ion mode and 966.0007 and 112.9855 for negative ion mode corresponding to the $\mathrm{m} / \mathrm{z}$ of reference ions.

Identification of compounds was based on Metlin database (https://metlin.scripps.edu) and compared with literature data.

\section{GC-MS analysis}

GC-MS was performed with a Shimadzu GC-2010 Plus gas chromatography instrument coupled to a Shimadzu QP2010 Ultra mass spectrometer equipped with fused silica capillary column ZB-5 MS ( $30 \mathrm{~m}, 0.25 \mathrm{~mm}$ i.d.) with a film thickness of $0.25 \mu \mathrm{m}$ (Phenomenex). Analysis were performed according to previously published method [14]. The oven temperature program was initiated at $50{ }^{\circ} \mathrm{C}$, held for $3 \mathrm{~min}$, then increased at the rate of $8{ }^{\circ} \mathrm{C} \mathrm{min}-1$ to $250{ }^{\circ} \mathrm{C}$, held for $2 \mathrm{~min}$. The spectrometers were operated in electron-impact (EI) mode, the scan range was 40-500 amu, the ionization energy was $70 \mathrm{eV}$ and the scan rate was $0.20 \mathrm{~s}$ per scan. Injector, interface and ion source were kept at 250, 250 and $220^{\circ} \mathrm{C}$, respectively. Split injection $(1 \mu \mathrm{L})$ was conducted with a split ratio of 1:20 and helium was used as carrier gas of $1.0 \mathrm{~mL} \mathrm{~min}-1$ flow-rate. The retention indices were determined in relation to a homologous series of n-alkanes (C8-C24) under the same operating conditions. Thujone was identified using a computer-supported spectral library [15].

\section{Antimicrobial activity assay in vitro}

The ethanolic and chloroform extracts were screened for antibacterial and antifungal activities by micro-dilution broth method according to both the European Committee on Antimicrobial Susceptibility Testing (EUCAST) (www. eucast.org) using Mueller-Hinton broth and MuellerHinton broth with $5 \%$ lysed sheep blood for growth of non-fastidious and fastidious bacteria, respectively or RPMI with MOPS for growth of fungi as we described elsewhere [16]. Minimal Inhibitory Concentration (MIC) of the tested derivatives were evaluated for the wide panel of the reference microorganisms from American Type Culture Collection (ATCC), including Gram-negative bacteria (Escherichia coli ATCC 25922, Salmonella Typhimurium ATCC14028, Klebsiella pneumoniae ATCC 13883, Pseudomonas aeruginosa ATCC 9027, Proteus mirabilis ATCC 12453), Gram-positive bacteria (Staphylococcus aureus ATCC 25923, Staphylococcus aureus ATCC 6538, Staphylococcus epidermidis ATCC 12228, Micrococcus luteus ATCC 10240, Bacillus subtilis ATCC 6633, Bacillus cereus ATCC 10876, Streptococcus pyogenes ATCC 19615, Streptococcus pneumoniae ATCC 49619, Streptococcus mutans ATCC 25175) and fungi (Candida albicans ATCC 10231, Candida parapsilosis ATCC 22019). Each experiment was repeated in triplicate. Representative data is presented.

\section{Statistical analysis}

All analysis were done in triplicates in order to prove their reproducibility. The results were expressed as mean \pm SD. Mann-Whitney test using GraphPad InStat 3 was performed to determine the significance of MIC 
values between the extracts. Statistical significance was set at $p<0.05$.

\section{Results}

\section{Phytochemical analysis}

Prior to comprehensive sample analysis, extracts from $A$. gmelinii with different polarities (ethanol, chloroform) were subjected to HPLC-DAD and LC-MS analysis in order to systemise the knowledge about phytochemical composition. Preliminary HPLC analysis resulted in identification of: umbelliferone (1), chlorogenic acid (2), rutin (3), scopoletin (7), luteolin (10) and apigenin (12). The numbering in parentheses is assigned according to the results of the following LC-MS analysis. Other unknown compounds (coumarins, flavonoids and phenolic acid derivatives) were also detected. Obtained HPLCDAD $(\lambda=325 \mathrm{~nm})$ chromatograms are presented on Additional files 1 and 2: Figures S1, S2. Quantitative determination of the compounds identified by this method was performed on the basis of 3-n determinations and converted into the content in $1 \mathrm{~g}$ of investigated extracts $[\mathrm{mg} / \mathrm{g}]$. The content of identified compounds is presented in Table 1. In both investigated extracts umbelliferone was identified, with 3-times higher content in chloroform extract compared to ethanolic. A simple coumarin scopoletin as well as two flavones - luteolin, apigenin were detected in chloroform extract and absent in ethanolic one. Chlorogenic acid - a polar depside, was dominant in ethanolic extract and absent in chloroform one. Additionally rutin was detected.

To confirm this, as well as identified other active constituents, ethanolic and chloroform extracts were subjected to LC-MS. 13 compounds were identified, as described below and listed in Table 2. Obtained chromatograms are presented on Additional files 3, 4 and 5: Figures S3-S5.

Table 1 HPLC- DAD analysis. The content of identified compounds in the extracts from A. gmelinii Weber ex Stechm. per gram of plant material used [mg/g] and (SD; RSD)

\begin{tabular}{|c|c|c|c|}
\hline Name & No & chloroform extract & ethanolic extract \\
\hline Umbelliferone & 1 & $\begin{array}{l}10.96 \\
(0.0011 ; 0.103)\end{array}$ & $\begin{array}{l}3.46 \\
(0.005 ; 0.074)\end{array}$ \\
\hline Chlorogenic acid & 2 & nd & $\begin{array}{l}156.98 \\
(0.032 ; 0.18)\end{array}$ \\
\hline Rutin & 3 & nd & $\begin{array}{l}7,03 \\
(0.021 ; 0.144)\end{array}$ \\
\hline Scopoletin & 7 & $\begin{array}{l}10.05 \\
(0.031 ; 0.176)\end{array}$ & nd \\
\hline Luteolin & 10 & $\begin{array}{l}5.07 \\
(0.028 ; 0,167)\end{array}$ & nd \\
\hline Apigenin & 12 & $\begin{array}{l}1.11 \\
(0.0002 ; 0.014)\end{array}$ & nd \\
\hline
\end{tabular}

The ESI-TOF-MS/MS spectrum of compound 1 in the negative ion mode at exhibited the molecular ion peak $\left[\mathrm{C}_{9} \mathrm{H}_{5} \mathrm{O}_{3}\right]^{-}$at $\mathrm{m} / \mathrm{z}=161.0229$ (theoretical mass $161.0244 ;-9.37 \mathrm{ppm}$ error). The compound was identified as umbelliferon. The ESI-TOF-MS/MS spectrum of compound 2 in the negative ion mode exhibited the molecular ion peak $\left[\mathrm{C}_{16} \mathrm{H}_{17} \mathrm{O}_{9}\right]^{-}$at $\mathrm{m} / \mathrm{z}=353.0889$ (theoretical mass $353.0878 ;-3.09 \mathrm{ppm}$ error). The compound was identified as chlorogenic acid or its isomer. The ESI-TOF-MS/MS spectrum of compound 3 in the negative ion mode at exhibited the molecular ion peak $\left[\mathrm{C}_{27} \mathrm{H}_{29} \mathrm{O}_{16}\right]^{-}$at $\mathrm{m} / \mathrm{z} 609.1494$ (theoretical mass 609.1450 ; -5.39 ppm error). Furthermore, the ESI-TOFMS/MS spectrum of compound 3 in the positive ion mode at exhibited the sodium adduct of molecular ion peak $\left[\mathrm{C}_{27} \mathrm{H}_{30} \mathrm{O}_{16} \mathrm{Na}\right]^{+}$at $\mathrm{m} / \mathrm{z}=633.1440$ (theoretical mass 633.1426 ; $-2.21 \mathrm{ppm}$ error) The compound was identified as rutin. The ESI-TOF-MS/MS spectrum of compound 4 in the negative ion mode at exhibited the molecular ion peak $\left[\mathrm{C}_{25} \mathrm{H}_{23} \mathrm{O}_{12}\right]^{-}$at $\mathrm{m} / \mathrm{z} 515.1207$ (theoretical mass 515.1195 ; $-2.33 \mathrm{ppm}$ error), additionally the ESI-TOF-MS/MS spectrum of compound 4 in the positive ion mode at exhibited the sodium adduct of molecular ion peak $\left[\mathrm{C}_{25} \mathrm{H}_{24} \mathrm{O}_{12} \mathrm{Na}\right]^{+}$at $\mathrm{m} / \mathrm{z} 539.1178$ (theoretical mass 539.1160; -3.35 ppm error) The compound was identified as dicaffeoylquinic acid isomer. The ESI-TOF-MS/MS spectrum of compound 5 in the negative ion mode at exhibited the molecular ion peak $\left[\mathrm{C}_{25} \mathrm{H}_{23} \mathrm{O}_{12}\right]^{-}$at $\mathrm{m} / \mathrm{z} 515.1209$ (theoretical mass $515.1195 ;-2.71 \mathrm{ppm}$ error) also the ESI-TOF-MS/MS spectrum of compound 5 in the positive ion mode at exhibited the sodium adduct of molecular ion peak $\left[\mathrm{C}_{25} \mathrm{H}_{24} \mathrm{O}_{12} \mathrm{Na}\right]^{+}$at $\mathrm{m} / \mathrm{z}$ 539.1164 (theoretical mass 539.1160 ; $-0.75 \mathrm{ppm}$ error) The compound was identified as dicaffeoylquinic acid isomer. The ESI-TOF-MS/MS spectrum of compound $\mathbf{6}$ in the positive ion mode at exhibited the molecular ion peak $\left[\mathrm{C}_{16} \mathrm{H}_{18} \mathrm{O}_{9} \mathrm{Na}\right]^{+}$at $\mathrm{m} / \mathrm{z}$ 377.0817 (theoretical mass 377.0843; $6.92 \mathrm{ppm}$ error) The compound was identified as scopolin. The ESI-TOF-MS/ MS spectrum of compound 7 in the positive ion mode at exhibited the molecular ion peak $\left[\mathrm{C}_{10} \mathrm{H}_{11} \mathrm{O}_{4}\right]^{+}$at $\mathrm{m} / \mathrm{z}$ 193.0491 (theoretical mass 193.0495; $2.27 \mathrm{ppm}$ error) The compound was identified as scopoletin. The ESI-TOF-MS/ MS spectrum of compound $\mathbf{8}$ in the negative ion mode at exhibited the molecular ion peak $\left[\mathrm{C}_{9} \mathrm{H}_{5} \mathrm{O}_{3}\right]^{-}$at $\mathrm{m} / \mathrm{z}$ 161.0491 (theoretical mass 161.0249; -2.98 ppm error) The compound was identified as 4-hydroxycoumarin. The ESITOF-MS spectrum of compound $\mathbf{9}$ in the negative ion mode at exhibited the molecular ion peak $\left[\mathrm{C}_{9} \mathrm{H}_{5} \mathrm{O}_{3}\right]^{-}$at $\mathrm{m} /$ $\mathrm{z}=161.0241$ (theoretical mass 161.0249; $1.96 \mathrm{ppm}$ error). The compound was identified as 3-hydroxycoumarin. The ESI-TOF-MS/MS spectrum of compound 10 in the negative ion mode at exhibited the molecular ion peak $\left[\mathrm{C}_{15} \mathrm{H}_{9} \mathrm{O}_{6}\right]^{-}$at $\mathrm{m} / \mathrm{z} 285.0406$ (theoretical mass 285.0405; - 
Table 2 Compounds identified by LC-MS in ethanolic and chloroform extracts from A. gmeilinii

\begin{tabular}{|c|c|c|c|c|c|c|}
\hline & Name / extract & {$[\mathrm{M}-\mathrm{H}]^{-}$} & {$[\mathrm{M}+\mathrm{H}]^{+}$} & {$[\mathrm{M}+\mathrm{Na}]^{+}$} & $\mathrm{ms} / \mathrm{ms}$ & Extract \\
\hline \multirow[t]{2}{*}{1} & Umbelliferon & 161.0229 & & & 133.0313 & Ethanolic \\
\hline & & & 163.0371 & & $107.0494 ; 91.0550$ & \\
\hline 2 & Chlorogenic acid & 353.0889 & & & 191.0562 & Ethanolic \\
\hline \multirow[t]{2}{*}{3} & Rutin & 609.1494 & & & $300.2078 ; 271.0242 ; 255.0310 ; 151.0020$ & \\
\hline & & & & 633.1440 & $331.1003 ; 324.0205$ & \\
\hline \multirow[t]{2}{*}{4,5} & Di-caffeoylquinic acid isomers & 515.1207 & & & $353.0893 ; 191.0561 ; 179.0350 ; 161.0239$ & Ethanolic \\
\hline & & & & 539.1178 & $377.0828 ; 359.0753 ; 215.0516 ; 185.0187$ & \\
\hline 6 & Scopolin & & & 377.0817 & 215.0304 & Ethanolic \\
\hline 7 & Scopoletin & & 193.0491 & & $\begin{array}{l}\text { 178.0268; 161.0220; 150.0305; 137. 0596; } \\
\text { 133.0280; 122.0361; } 105.0280\end{array}$ & Ethanolic \\
\hline 8 & 4-hydroxycoumarin & 161.0249 & & & $133.0297 ; 117.0333$ & Chloroform \\
\hline 9 & 3-hydroxycoumarin & 161.0241 & & & - & Chloroform \\
\hline 10 & Luteolin & 285.0406 & & & $175.0397 ; 151.0023 ; 133.0282$ & Chloroform \\
\hline 11 & Isorhamnetin & 315.0513 & & & $300.0276 ; 285.0405 ; 271.0248 ; 255.0299 ; 151.0039$ & Chloroform \\
\hline 12 & Apigenin & 269.0450 & & & $225.0554 ; 151.0018 ; 149.0244 ; 117.0329$ & Chloroform \\
\hline 13 & Rhamnazin & 329.0679 & & & 314.0450; 299.0209; 151.0031 & Chloroform \\
\hline
\end{tabular}

0.48 ppm error) The compound was identified as luteolin. The ESI-TOF-MS/MS spectrum of compound 11 in the negative ion mode at exhibited the molecular ion peak $\left[\mathrm{C}_{16} \mathrm{H}_{11} \mathrm{O}_{7}\right]^{-}$at $\mathrm{m} / \mathrm{z}=315.0513$ (theoretical mass 315.0510; $-0.87 \mathrm{ppm}$ error) The compound was identified as isorhamnetin. The ESI-TOF-MS/MS spectrum of compound 12 in the negative ion mode at exhibited the molecular ion peak $\left[\mathrm{C}_{15} \mathrm{H}_{9} \mathrm{O}_{5}\right]^{-}$at $\mathrm{m} / \mathrm{z}=269.0450$ (theoretical mass $269.0455 ; 2.03$ ppm error). The compound was identified as apigenin. The ESI-TOF-MS/MS spectrum of compound 13 in the negative ion mode at exhibited the molecular ion peak $\left[\mathrm{C}_{17} \mathrm{H}_{13} \mathrm{O}_{7}\right]^{-}$at $\mathrm{m} / \mathrm{z}=329.0679$ (theoretical mass 329.0667 ; $-3.71 \mathrm{ppm}$ error) The compound was identified as rhamnazin.

Quantitative determination of known toxic phytochemicals thujone was performed by GC-MS method for both extracts. The content was between 0,12-0,16\% thus we assume as low and without influence on the activity.

\section{Antimicrobial activity}

Reference strains of bacteria and fungi enlisted in Table 3 were taken for preliminary screening of antimicrobial activity using micro-broth dilution method. It was shown that the assayed extracts inhibited growth of the reference microorganisms with MIC of 1.25 - > $20 \mathrm{mg} / \mathrm{ml}$, depending on the strains and solvents used. The biological activity of chloroform and ethanolic extracts was comparable (Mann-Whitney test, $p=0.78$ ). The most sensitive were gram-positive bacteria represented by staphylococci, Micrococcus luteus and Bacillus spp. (MIC $=1.25-5 \mathrm{mg} / \mathrm{ml})$ and yeasts represented by Candida spp. $(\mathrm{MIC}=2.5-$
$5 \mathrm{mg} / \mathrm{ml}$ ), irrespective of the assayed extract. The lowest biological activity of both extracts was observed against gram-negative rods

\section{Discussion}

Different Artemisia species are described as producers of metabolites with an antimicrobial activity [10, 17-19]. However, to our best knowledge, this is so far the first report of antimicrobial activity of A. gmelinii extracts. The phytochemical characteristic of tested extracts was different, but in general only slightly higher activity against Gram-negative bacteria was noticed for ethanolic extract in comparison to the chloroform one. In ethanolic A. gmelinii extract the high level of chlorogenic acid was observed. Recent studies showed that chlorogenic acid bound to the outer membrane, disrupted the membrane, exhausted the intracellular potential, and released cytoplasm macromolecules, which led to the death of cell [20]. That may be also an explanation of a more frequent bactericidal activity of ethanolic extract for most of the tested strains. Determining the MBC value allowed to establish the activity to kill bacteria or inhibit its growth. Antimicrobial agents are usually regarded as bactericidal if $\mathrm{MBC}$ value is higher no more than four times the MIC value [21]. The low values of $\mathrm{MBC} / \mathrm{MIC}$ ratio (1-4) for ethanolic extract suggested its bactericidal power for majority of bacterial and fungal strains except for bacteriostatic activity against spore-forming $B$. cereus.

The data shown by Poiata et al. [22] indicated that among ethanol, methanol and hexane extracts from Artemisia absinthium, Artemisia annua and Artemisia vulgaris alcoholic extracts were more effective against 


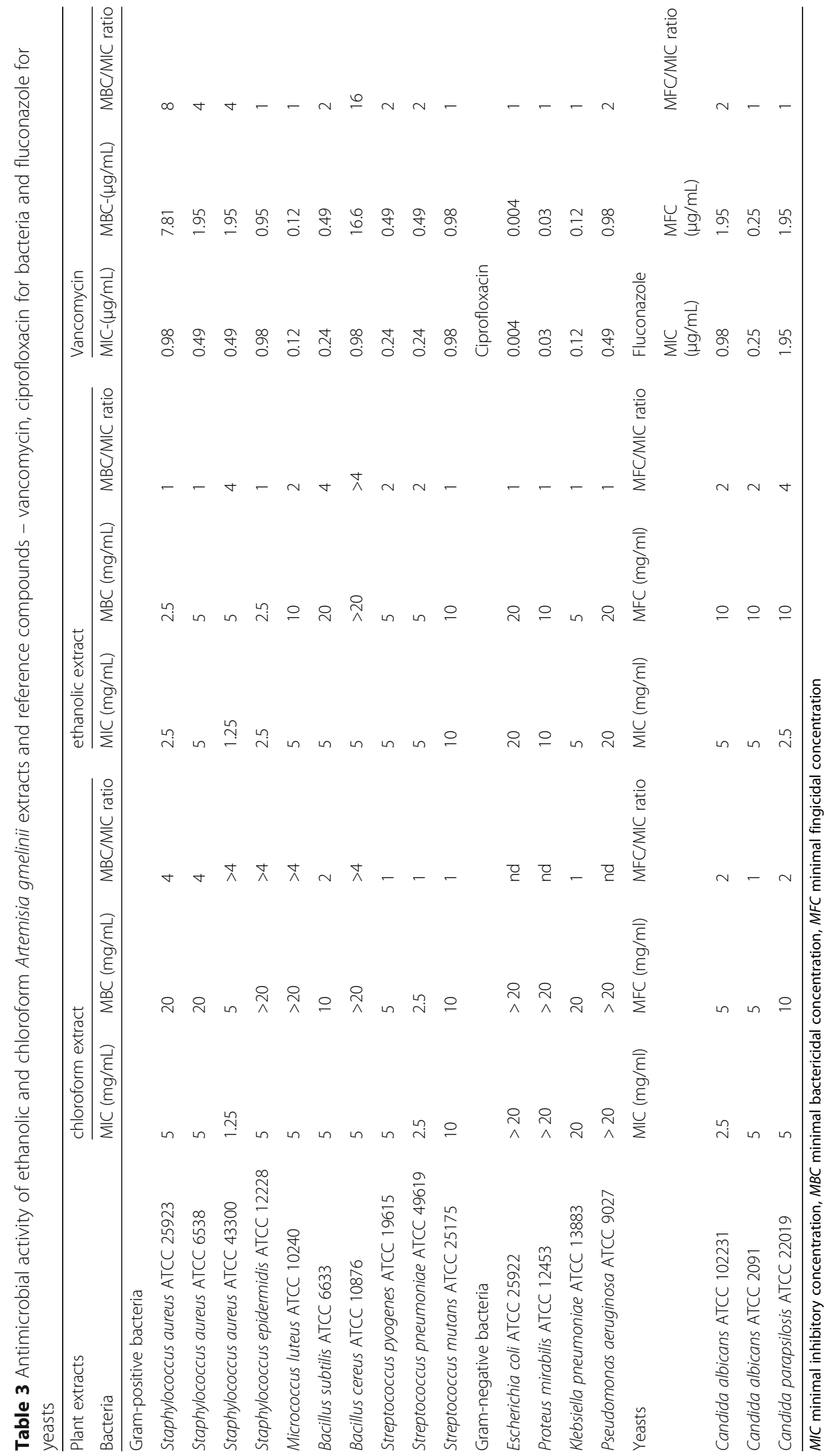


tested microorganisms. However, all plants' extracts have moderate or no activity against Gram-negative bacteria. The higher microbial activity of n-hexane, ethyl acetate and menthol extracts observed in other studies, could be related to the higher concentration of active antimicrobial agents like terpenoids, phenolics and volatile oils in Artermisia spp. [17, 23].

It is widely thought that some coumarins, including umbelliferone, scopoletin and furanocoumarins play important fungicidal roles in plants. In general, umbelliferone shows no antifungal activities and very weak antibacterial activities irrespective of the test method and sample purity [24-26]. In our study, the chloroform extract of A. gmelinii showed higher amount of umbelliferone that may be the cause of lower value of MFCs for tested fungi in comparison to the ethanolic extract.

Standardized MIC testing methods were used by Ahameethunisa and Hopper [10, 17] to determine the antimicrobial activity of $A$. nilagirica and $A$. parviflora extracts from India. Higher activity of both etanolic and chloroform A. nilagrica extracts was revealed in their studies in comparison to the one presented in our study what may be caused by different geographical origin of the plants and species and their phytochemical composition. Chloroform extracts of $A$. nilagrica were high in alkaloids, flavonoids, phenols, and terpenoids, similarly to the ethanolic extract which was richer with tannins, saponins and quinines, though [10].

In other studies agar well diffusion method was the only one used to detect antimicrobial activities of $A$. annua leaf extract [19], A. absinthium extract [26] and Artemisia sp. methanolic extracts recovered by different extraction techniques [18]. The well or disk diffusion methods provide qualitative results, appropriate for screening selection only. This method is not appropriate to give quantitative results allowing for MIC dtermination, because it is not possible to define precisely the amount of the extract diffused into the agar medium. Sometimes it is impossible to distinguish whether the lack of antimicrobial activity is a result of the extract's action or a lack of its diffusion to agar. Moreover, since the bacterial growth does not mean the bacterial death, this method cannot distinguish bactericidal or bacteriostatic effect of the extracts. We would like to point out that due to the use of standardized methods in antimicrobial activity testing of plant extracts or essential oils, data can be trustworthy and allow researchers to compare the results.

In general, 13 compounds were identified in the analyzed extracts. To the best of our knowledge, this is the first ever work that shows the identification of rhamnazine, umbelliferone, 3-hydroxycoumarin and 4-hydroxycoumarin in the genus Artemisia. Moreover, for the first time in A. gmelinii species, luteolin, rutin, isorhamnetin and scopolin were identified, even though these substances were previously determined in other species of Artemisia [27-29]. The presence of apigenin, scopoletin, chlorogenic acids and two dicaffeoylquinic acid isomers have also previously been reported $[12,13,30]$. Additionally it is worth to highlight that low level of thujone was determined in the tested extract so there should be no potential influence of the activity as well as no toxicity towards the human. Thujone is a natural monoterpene ketone present in variable amounts in a large number of plants, such as Salvia, Tanacetum and Artemisia species. Thujone has neurotoxic action, causing tonicclonic convulsions and also exhibits hepatotoxicity and porphyrogenic activity [31]. However at the same time it should be noted that the toxic activity of the extracts should not be associated exclusively with thujones as, in addition to the thujone content, the amount and toxicity of other constituents should be taken into consideration when making risk assessment and determining the regulatory status of plants in food and medicines [32].

\section{Conclusion}

There is an urgent need, to work towards the development of safer antimicrobial agents, that are expected to be renewable, non-petrochemical, naturally ecofriendly and easily obtainable. The extracts of wormwood Artemisia gmelinii have shown a wide spectrum of antibacterial and antifungal activity. For the first time in $A$. gmelinii species, luteolin, rutin, isorhamnetin and scopolin were identified. Determining of the most potential compounds of Artemisia gmelinii can be used to develop effective antibacterial and antifungal agents.

\section{Supplementary information}

Supplementary information accompanies this paper at https://doi.org/10. 1186/s12906-019-2719-x. Additional file 1: Figure S1. HPLC-DAD chromatogram $(\lambda=325 \mathrm{~nm})$ -
chloroform extract from A. gmelinii Weber ex Stechm.

Additional file 2: Figure S2. HPLC-DAD chromatogram $(\lambda=325 \mathrm{~nm})$ ethanolic extract from A. gmelinii Weber ex Stechm.

Additional file 3: Figure S3. The BPC chromatogram of ethanolic extract of Artemisia in negative ionization mode.

Additional file 4: Figure S4. The BPC chromatogram of ethanolic extract of Artemisia in positive ionization mode.

Additional file 5: Figure S5. The BPC chromatogram of chloroform extract of Artemisia in negative ionization mode.

\section{Abbreviations}

CID energy: Collision-induced dissociation energy; GACP: Good cultural and collection practices; GC-MS: Gas chromatography mass spectrometry; HPLCDAD: High performance liquid chromatography with a visible diode array detector; LC-MS: Liquid chromatography-mass spectrometry; MBC: Minimal bactericidal concentration; MFC: Minimal fungicidal concentration;

MIC: Minimal inhibitory concentration

Acknowledgements

Not applicable 


\section{Authors' contributions}

ASM, IKG, KSW, contributed with the design of the experiments, performed the experiments, analyzed and discussed the data, and wrote the paper; AM, ZBS, contributed with the design of the experiments, discussed the data and wrote the paper; KKW, AJ, TB performed the experiments and analyzed the data. All authors read and approved the final manuscript.

\section{Funding}

The authors have no support or funding to report.

\section{Availability of data and materials}

The datasets analyzed during the current study are available from the corresponding author on reasonable request.

\section{Ethics approval and consent to participate}

Not applicable

\section{Consent for publication}

Not applicable

\section{Competing interests}

The authors declare that they have no competing interests.

\section{Author details}

${ }^{1}$ JSC Asfendiyarov Kazakh National Medical University, Republic of Kazakhstan, 94 Tolebi Str. Almaty 050000, Republic of Kazakhstan. ${ }^{2}$ Department of Pharmaceutical Microbiology with Laboratory for Microbiological Diagnostics of Medical University of Lublin, 1 Chodzki Street, 20-093 Lublin, Poland. ${ }^{3}$ Department of Pharmacognosy with Medicinal Plant Unit of Medical University of Lublin, 1 Chodzki Street, 20-093 Lublin, Poland.

\section{Received: 29 November 2018 Accepted: 16 October 2019}

\section{Published online: 28 October 2019}

\section{References}

1. Yuan HD, Jin GZ, Piao GC. Hepatoprotective effects of an active part from Artemisia sacrorum Ledeb. Against acetaminophen-induced toxicity in mice. J Ethnopharmacol. 2010;127:528-33.

2. Chen YL, Chen YS. Asteraceae in Shi, Z., Flora of China. Science Press (Beijing) \& Missouri Botanical Garden Press (St. Louis), 2011, Vol 20-21, 688.

3. Yuan HD, Jin GZ, Piao GC. Protective effects of the active part of Artemisia sacrorum Ledeb. Against acetaminophen-induced liver injury in mice. Biol Pharm Bull. 2009:32:1683-8.

4. Desiree CKR, Renem FKP, Jonas K. Antibacterial and antifungal activity of the essential oil extracted by hydro-distillation from Artemisia annua grown in West-Cameroon. J Pharmacol Toxicol. 2013;4:89-94.

5. Appalasamy S, Lo KY, Ch'ng SJ, Nornadia K, Othman AS, Chan LK Antimicrobial activity of artemisinin and precursor derived from in vitro plantlets of Artemisia annua L. Biomed Res Int 2014, 215872. doi: https://doi.org/10.1155/2014/215872.

6. Verdian-Rizi M, Sadat-Ebrahimi E, Hadjakhoondi A, Fazeli M, Pirali HM. Chemical composition and antimicrobial activity of Artemisia annua L. essential oil from Iran. Planta Med. 2008;7:58-62.

7. Li Y, Hao-Bin H, Xu-Dong Z, Ji-Hua Z, Li-Ping L. Composition and antimicrobial activity of essential oil from the aerial part of Artemisia annua. Planta Med. 2011;5:3629-33.

8. Juteau F, Masotti V, Bessière JM, Dherbomez M, Viano J. Antibacterial and antioxidant activities of Artemisia annua essential oil. Fitoterapia. 2002;73: 532-5.

9. Cha JD, Jung EK, Kil BS, Lee KY. Chemical composition and antibacterial activity of essential oil from Artemisia feddei. J Microbiol Biotechnol. 2007;17: 2061-5.

10. Ahameethunisa AR, Hopper W. Antibacterial activity of Artemisia nilagirica leaf extracts against clinical and phytopathogenic bacteria. BMC Complem Altern Med. 2010;10:1-6

11. Zhigzhitzhapova SV. Chemical composition of essential oils from Artemisia gmelinii web. Et Stechm., growing in Central Asia. Chem Plant Raw Mat. 2010;2:131-3.

12. Chemesova II, Belenovskaya LM, Markova LP. Phenolic compounds of Artemisia gmelinii. Chem Nat Comp. 1983;19:365-6.
13. Könczöl A, Béni Z, Sipos MM, Rill A, Háda V, Hohmann J, Máthé I, Szántay C Ir, Keseru GM, Balogh GT. Antioxidant activity-guided phytochemical investigation of Artemisia gmelinii Webb. Ex Stechm.: isolation and spectroscopic challenges of 3,5-O-dicaffeoyl (epi?) quinic acid and its ethyl ester. J Pharm Biomed Ana. 2012;59:83-9.

14. Skalicka-Wozniak K, Walasek M, Ludwiczuk A, Glowniak K. Isolation of terpenoids from Pimpinella anisum essential oil by high-performance counter-current chromatography. J Sep Sci. 2013;36:2611-4.

15. Konig WA, Joulain D, Hochmuth DH, 2008 Mass Finder 4.0, (http://www massfinder.com).

16. Sermukhamedova O, Wojtanowski KK, Widelski J, Korona-Głowniak I, Elansary HO, Sakipova Z, Malm A, Głowniak K, Skalicka-Woźniak K. Metabolic profile of and antimicrobial activity in the aerial part of Leonurus turkestanicus V.I. Krecz. Et Kuprian. From Kazakhstan. J AOAC Int. 2017;100:1700-5.

17. Ahameethunisa AR, Hopper W. In vitro antimicrobial activity on clinical microbial strains and antioxidant properties of Artemisia parviflora. Ann Clin Microbiol Antimicrob. 2012;11:1-7.

18. Karabegovic I, Nikolova M, Velickovic D, Stojicevic S, Veljkovic V, Lazic M. Comparison of antioxidant and antimicrobial activities of methanolic extracts of the Artemisia sp recovered by different extraction techniques. Chin J Chem Eng. 2011;19:504-11.

19. Tajehmiri A, Issapour F, Moslem NM, Lakeh MT, Kolavani MH. In vitro antimicrobial activity of Artemisia annua leaf extracts against pathogenic bacteria. Adv Stud Biol. 2014;6:93-7.

20. Lou Z, Wang H, Zhu S, Ma C, Wang Z. Antibacterial activity and mechanism of action of chlorogenic acid. J Food Sci. 2011;6:M398-403.

21. French GL. Bactericidal agents in the treatment of MRSA infections - the potential role of daptomycin. J Antimicrob Chemother. 2006;58:1107-17.

22. Poiată A, Tuchiluş C, Ivănescu B, Ionescu A, Lazăr MI. Antibacterial activity of some Artemisia species extract. Rev Med Chir Soc Med Nat lasi. 2009;113: $911-4$.

23. Suresh J, Reddy V, Rajan D, Ihsanullah M, Khan MN. Antimicrobial activity of Artemisia abortanum and Artemisia pallens. IJPPR. 2011:3:18-21.

24. Mazimba O. Umbelliferone: sources, chemistry and bioactivies review. Bulletin of Faculty of Pharmacy, Cairo University. 2017;55:223-32.

25. Ji Q, Ge Z, Ge Z, Chen K, Wu H, Liu X, Huang Y, Yuan L, Yang X, Liao F. Synthesis and biological evaluation of novel phosphoramidate derivatives of Coumarin as chtin synthase inhibitors and antifungal agents. Eur J Med Chem. 2016:108:166-76.

26. Habibipour R, Rajabi M. Antibacterial effects of Arctium lappa and Artemisia absinthium extracts in laboratory conditions. J Herb Med Pharmacol. 2015;4: $133-7$.

27. Shin NR, Ryu HW, Ko JW, Park SH, Yuk HJ, Kim HJ, Kim JC, Jeong SH, Shin IS. Artemisia argyi attenuates airway inflammation in ovalbumin-induced asthmatic animals. J Ethnopharmacol. 2017;209:108-15

28. Zhang L, Tu ZC, Wang H, Fu ZF, Wen QH, Fan D. Metabolic profiling of antioxidants constituents in Artemisia selengensis leaves. Food Chem. 2015:186:123-32.

29. Tan RX, Zheng WF, Tang HQ. Biologically active substances form genus Artemisia. Planta Med. 1998;64:295-302.

30. Zeng W, Quesheng Zhang Q, Liang H. Flavonoids from Artemisia gmelinii web. Ex Stechm. J Chin Pharm Sci. 2014;23(7):496-9.

31. Sotiropoulou NSD, Kokkini MK, Megremi SFP, Daferera DJ, Skotti EP, Kimbaris AC, Polissiou MG, Tarantilis PA. Determination of $\alpha$ - and $\beta$-thujone in wormwood and sage infusions of Greek flora and estimation of their average toxicity. Curr Res Nutr Food Sci. 2016;4:152-60.

32. Radulovic NS, Gencic MS, Stojanowic NM, Randjelovic PJ, Stojanovic-Radic ZZ, Stojiljkovic NI. Toxic essential oils. Part V: behaviour modulating and toxic properties of thujones and thujone-containing essential iols of Salvia officinalis L., Artemisia absinthium L., Thuja occidentalis L. and Tanacetum vulgare L. Food Chem Toxicol. 2017:105:355-69.

\section{Publisher's Note}

Springer Nature remains neutral with regard to jurisdictional claims in published maps and institutional affiliations. 